\title{
Performance of Ecological Cement-Based Composites Containing Sugarcane Bagasse Ash - A Review
}

\author{
Marco A. Maldonado-García ${ }^{1}$, Pedro Montes-García ${ }^{1}$, Pedro L. Valdez-Tamez ${ }^{2}$ \\ ${ }^{1}$ Instituto Politécnico Nacional - CIIDIR Oaxaca \\ Hornos 1003, Colonia Noche Buena, Santa Cruz Xoxocotlán, C.P. 71230, Oaxaca, México \\ mmaldonadog1500@alumno.ipn.mx; pmontesgarcia@gmail.com \\ ${ }^{2} \mathrm{Ph} . \mathrm{D}$. Universidad Autónoma de Nuevo León - Facultad de Ingeniería Civil \\ Cd. Universitaria S/N, San Nicolás de los Garza, C.P. 66451, Nuevo León, México \\ pedro.valdeztz@uanl.edu.mx
}

\begin{abstract}
In recent years the sugarcane bagasse ash (SCBA) has been used to produce environmentally-friendly cement-based composites. The SCBA is an agricultural waste which is obtained as by-product from the combustion of sugarcane bagasse in sugar mills. This ash is available in large quantities in emerging countries such as Brazil, India, Thailand and Mexico, and its disposal in open dumps is causing different environmental issues. A number of researchers report that the SCBA from sugar mills needs a post-treatment such as recalcination, grinding, sieving or the combination of these methods in order to enhance its pozzolanic activity. After processing, up to $30 \%$ of SCBA can be used as a partial Portland cement replacement in composites. This replacement may cause microstructural changes in the cementitious matrix and the improvement of the mechanical properties in composites containing it. However, studies on the durability of such composites are required. This paper focuses on the performance of cement-based composites containing treated SCBA. The microstructural, mechanical and some durability properties of those composites are discussed. This literature review is useful to carry out further researches about the durability of reinforcement embedded in cement-based composites containing SCBA (SCBAC).
\end{abstract}

Keywords: Agricultural waste, Post-treatment method, Pozzolanic activity, Ecological concrete, Durability.

\section{Introduction}

The sugarcane bagasse ash (SCBA) is a by-product material generated during the combustion process of the sugarcane bagasse in the boilers of sugar mills. It is estimated that approximately 15 million tons of SCBA are produced in sugar mills around the world [1] and it is mostly available in emerging countries such as Brazil, India, Thailand and Mexico. This ash causes different environmental issues when is deposited in open dumps. The improper disposal of the SCBA pollutes the air because of the fine particles in the ash [2], also pollutes the water in nearby rivers and ground water due to the transport of the SCBA particles by the rainwater [3]. Even, it has been reported that the SCBA may causes soil contamination when is used as fertilizer because of its lack of nutrients and silica content [4].

The SCBA contains silicon, aluminium and iron oxides as major compounds and research results indicate that in some cases up to $30 \%$ of this ash can be used as a partial Portland cement replacement in cement-based composites. This is without having negative effects on the physical and mechanical properties of the composites due to the pozzolanic properties of the ash $[2,5-10]$. The authors of these works claim that the use of SCBA in those composites can diminish environmental pollution; furthermore, the negative effects to the environment due to cement production can be reduced by the use of SCBA obtaining ecological cement-based composites.

Additional research report that the use of SCBA as a partial Portland cement replacement improves the microstructural and mechanical properties of cement-based composites [2, 5, 10-12]. The authors suggest that the durability of those composites can also be improved; however, there is not enough research to validate this statement. Based on the aforementioned dilemma, a literature review about the effect of SCBA on the microstructural, mechanical and durability properties of cement-based composites is presented in this paper. 


\section{Properties and post-treatments for the SCBA to be used in SCBAC}

The SCBA is conformed by particles with different sizes and shapes $[8,10,13]$. This might be attributed to the nature of the bagasse which is made up of fiber bundles (cellulose, hemicellulose and lignin), vessel, epidermal cells and small number of soluble solids [14-15] and the pyrolysis process of the sugarcane bagasse [4] which depends of the efficiency of the boilers in sugar mills [16]. In general, the SCBA display a monodisperse distribution of its particles ranging in tenths of microns (approximately 0.4 to $175 \mu \mathrm{m}$ ) depending of the temperature and air flow during the burning process of the bagasse $[1,4,10,12,17]$.

After burning the sugarcane bagasse, the residual ash is mainly composed by silicon, aluminium and iron oxides as major compounds (approximately 85\%) [18]. It also contains other compounds such as calcium, potassium and sodium. Furthermore, unburned particles represented by the loss on ignition value are in the ash. The variability on the chemical composition of the SCBA can be attributed to the combustion process of the bagasse but also to the maturity and harvesting methods of the sugarcane [19].

Researchers report that the SCBA has pozzolanic properties to be used as cement replacement in cement-based composites $[1,7,8,10]$. The pozzolanic activity of the ash has been attributed to reactions between the amorphous silicon, aluminium and iron oxides with the calcium hydroxide from cement hydration and water. From a scientific point of view, the pozzolanic activity of SCBA ashes can differ because the nature and the calcination process of the bagasse $[7,11,17,20]$.

According to the above, most researchers have suggested and used different post-treatments for the SCBA such as recalcination, grinding, sieving or the combination of these methods to enhance the pozzolanic activity of the SCBA. Post-treatments to the SCBA have been also implemented to diminish workability problems during the mixing process of fresh mixtures because the different sizes and shapes of the SCBA particles. A recent research reported that the pozzolanic activity of the SCBA increased at temperatures up to $700^{\circ} \mathrm{C}$; however, a higher temperature reduced the pozzolanic activity of the ash due to crystallization of its particles. A grinding process increased the fineness of SCBA particles, but the material needs to be ground until reaching a particle size below $45 \mu \mathrm{m}$. Sieving helped removing coarse particles from the SCBA and gave a comparable pozzolanic activity index than a control mixture. As a result, the authors recommend a grinding process after sieving to increase pozzolanic activity of the ash [8].

Grinding (and ultrafine grinding) appears to be the most used post-treatment [21-24]; however, a grinding process requires several hours to be effective and hence a high energy demand. On the other hand, sieving appears as the less energy demanding post-treatment for the SCBAwith proper pozzolanic performance of the ash in cement-based composites [8, 10, 25-26]. A research reported an insignificant difference on the pozzolanic performance when comparing a SCBA subjected to different sieving and grinding process or the combination of these methods [10]. The authors claimed that a sieving process through the $75 \mu \mathrm{m}$ sieve for 5 minutes is enough to considerably improve the pozzolanicity of SCBA. Those results form part of a long-term on-going research about durability of cement-based composites containing sieved SCBA. A comparison between the morphological characteristics of the as received and the sieved SCBA (through the ASTM $75 \mu \mathrm{m}$ sieve) is presented in Fig. 1. The figure shows that the SCBA has a morphology consisting in prismatic, agglomerated, spherical and fibrous unburned particles; the figure also evidences the reduction of the amount of coarse particles when the SCBA is subjected to sieving. 


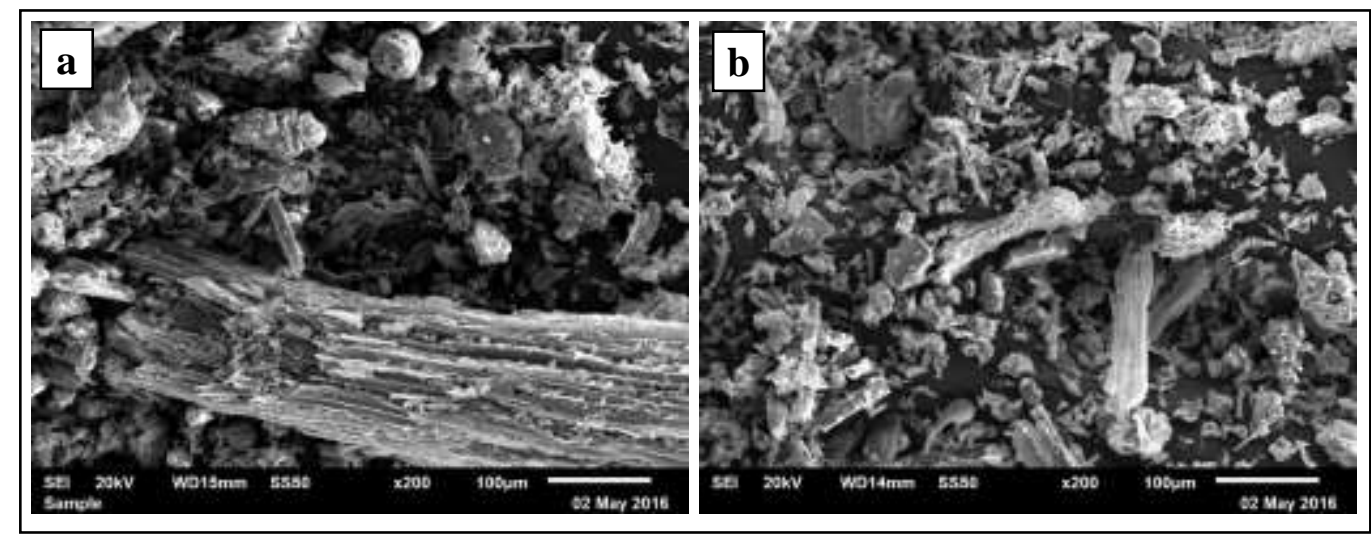

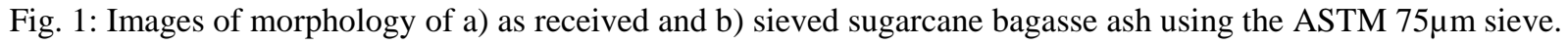

\section{Rheological properties of SCBAC}

Researchers report that the use of SCBA as partial cement replacement has adverse effects on the slump of cementbased composites causing workability issues [3]. The presence of the agglomerated and fibrous unburned particles in the ash and the different sizes and shapes of the burnt particles can be blamed for this fact [27-28]. Nevertheless, workability problems can be reduced when the SCBA is subjected to a sieving or grinding treatment reducing its particles sizes and shapes. The workability problems are mostly present when using as received of sieved SCBA [10, 12, 26, 29]; in addition, these problems have been also reported when the SCBA is subjected to a grinding process to reduce its particle size [6, 9 , $21,30]$.

It has been reported that the SCBA reduces the flowability of fresh mixtures because an increase of friction between the particles of the ash which are different in size and shape [28]. A mechanism for this in cement pastes and mortars containing SCBA as showed in Fig. 2 has been proposed. It can be observed that the SCBA tend to agglomerate during the mixing process. According to the authors, the addition of another supplementary cementitious material such as fly ash could have a beneficial effect on workability of cement-based composites added with a SCBA subjected to a low-energy demand posttreatment.

The use of chemical additives for cement-based composites containing SCBA, even when the SCBA has been subjected to a post-treatment, is mandatory in order to keep the water/cementitious materials ratio during the mixing process of the composites $[6,9,12,21,29,31-32]$. It has been reported that the most compatible chemical additive to improve the workability of the cement-based composites is a polycarboxylate ether-based superplasticizer [27].

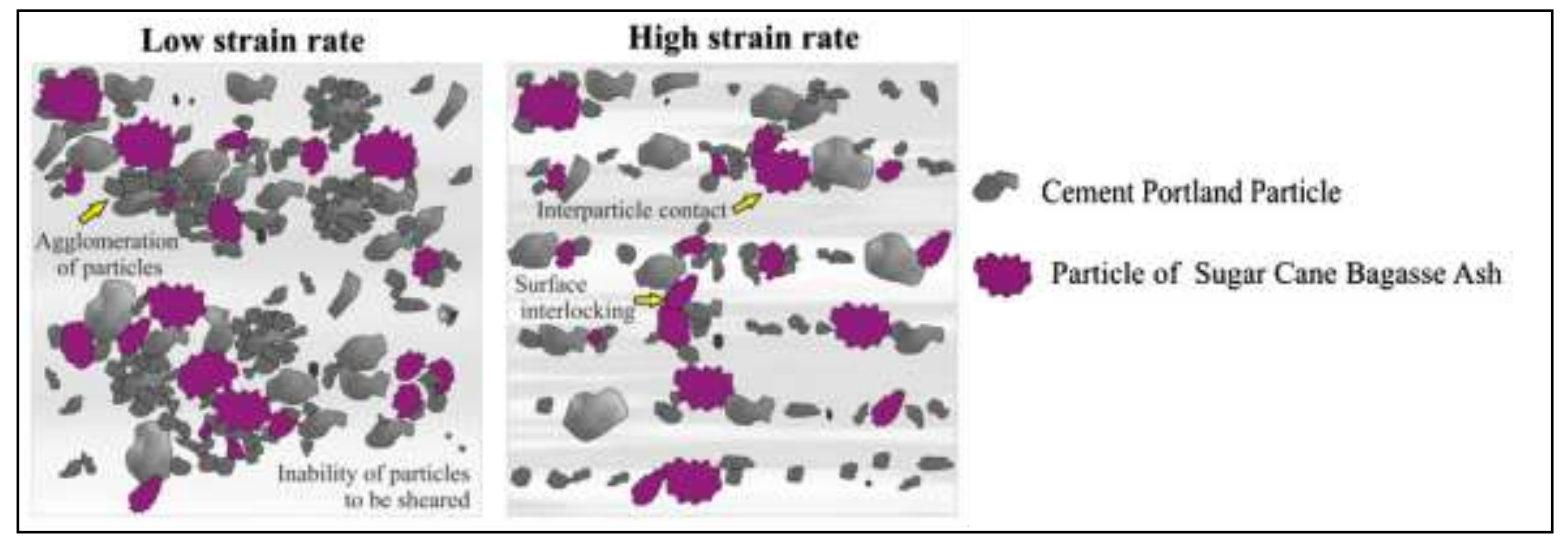

Fig. 2: Schematic representation of the rheological behaviour of SCBA in cement-based composites, adapted from [28]. 
According to the previous statements, the evaluation of the rheological properties of cement-based composites containing SCBA could be a mandatory parameter in order to select a proper chemical additive and the most adequate dosage to keep flowability and workability of fresh mixtures [27-28]; leading to the use of a minimum quantity of the chemical additive which also causes environmental concerns when is produced.

\section{Microstructural properties of SCBAC}

The use of SCBA in cement-based composites leads to the change of the cementitious matrix making it more complex. The modification of the cementitious matrix can be attributed to pozzolanic reactions and to a filler effect of the SCBA. Apparently, each post-treatment for the SCBA has an important influence in which mechanism predominate in the changes of the cementitious matrix. When the SCBA is subjected to a recalcination process (between 600 to $800^{\circ} \mathrm{C}$ ), the pozzolanic effect has a greater influence in changing the microstructure of the composites [4, 20]. With a grinding process, both the pozzolanic reactions and the filler effect could occur due to the fineness of the SCBA particles [6, 33-34]. Moreover, with a sieving process, pozzolanic reactions also occur but probably at longer ages when compared to recalcination and grinding [10].

The pozzolanic effect of the SCBA is attributed to the development of additional cementitious compounds such as calcium silicate hydrate (C-S-H) and calcium-aluminum silicate hydrate (C-A-S-H) $[4,10,12,29,35]$. The development of these additional cementitious compounds from the pozzolanic reactions could continue at longer ages (more than 28 days) creating a complex cementitious matrix as observed in Fig. 3 [10].

The filler effect occurs due to the finer or crystalline particles in the ash. It has been reported that the finer particles of the SCBA modify the connectivity of the porous system and segment large pores in the cementitious matrix of cementbased composites [31]. Other researchers affirm that some particles of as received SCBA from sugar mills could not have appropriate pozzolanic properties because its high crystallinity $[4,19]$. This suggest that the SCBA could also used as inert material in cement-based composites.

Aa a summary, the changes of the cementitious matrix could help to enhance the mechanical and durability properties of cement-based composites creating a denser and impermeable matrix.

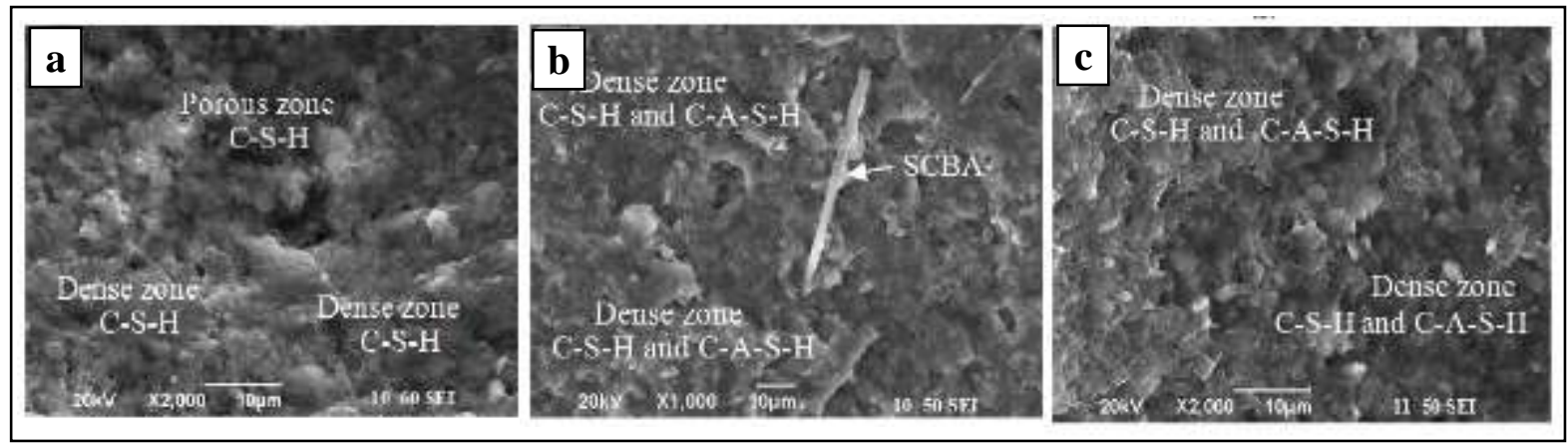

Fig. 3: Micrographs of mortars containing a) 0, b) 10 and c) 20\% of sieved SCBA taken after 600 days, adapted from [10].

\section{Compressive strength of SCBAC}

Certainly, the post-treatment method used for the SCBA accounts for the pozzolanic reactions and the filler effect of the ash to increase the compressive strength. Recalcination appears to be the most adequate process to enhance the pozzolanic activity of the SCBA and hence to increase the compressive strength in cement-based composites containing it [8]. Grinding could give both pozzolanic reactions and the filler effect in order to increase the compressive strength of the composites [34]. Sieving has also a positive effect on increasing the compressive strength in cement-based composites due to pozzolanic reactions of the SCBA [8,25]. Nevertheless, a large amount of unburned particles can remain in the SCBA subjected to sieving [18] and this could affect some durability properties of the composites. 
Research results affirm that the addition of SCBA as partial cement replacement increases the compressive strength of cement-based composites [2, 6, 9, 11-12, 29, 31,33]. This increase in compressive strength has been mainly attributed to the pozzolanic activity of the SCBA. Furthermore, the filler effect of some SCBA particles could also have a positive effect on the compressive strength of cement-based composites [6, 19, 33-34]. However, some studies report that the increase in compressive strength of those composites occur after 28 days [3, 9-10]. A recent research also shows that the addition of SCBA helps to reduce the loss of strength when the cement-based composites are exposed to elevated temperatures [36].

\section{Durability properties of SCBAC}

As discussed in previous sections, the selected post-treatment to enhance the pozzolanic activity of the SCBA also play an important role in the performance of composites containing it. Recalcination influences the pozzolanic activation of the SCBA particles which in turn to refine the pore structure of the cementitious matrix and it could improve some durability properties of composites [4,7]. A grinding process increase the fineness of the SCBA and this improve the pore size distribution of cement-based composites in order to enhance its durability properties besides pozzolanic activity of the ash $[11,23]$. The sieving process does not reduce the loss on ignition content as recalcination or grinding do; however, these particles could have positive effects as binding media for chloride ions in terms of durability [10,26].

Researchers reported that the addition of SCBA has a positive effect in the durability properties of cement-based composites regardless to the selected post-treatment for the SCBA [5, 11-12, 26]. Different test such as water absorption, sorptivity, chloride ion penetration resistance, chloride ion diffusion and electrical resistivity have been evaluated in those studies. According to the authors, water absorption can be reduced in the composites in about $50 \%$ after 90 days of curing, which is caused by the hygroscopic nature of the SCBA [5, 28]. Sorptivity also decreases with the addition of SCBA in the composites making an impermeable cementitious matrix; additionally, sorptivity is less affected by the curing time [5-6, 11]. Chloride ion penetration and chloride ion diffusion are also decreased (in about 50\%) in composites containing SCBA due to microstructural changes on the cementitious matrix [5, 11, 23, 26, 37]. Finally, the electrical resistivity of cement-based composited is increased when using SCBA which aim to an improvement in quality of the composites [26, 37].

Despite the reported advantages in durability of cement-based composites containing SCBA, an evaluation of long-term durability of composites containing SCBA is necessary [38-39]. The performance of steel embedded in composites containing SCBA against corrosion must be addressed. Only few studies report results from electrochemical testing. Two studies contrast about the addition of SCBA and its effect on the corrosion of reinforced steel embedded in cement-based composites [40-41]. However, those studies were carried out considering a short-term period for testing leading to some uncertainties. Recent researches show that the SCBA does not have a negative effect on increasing the corrosion risk of reinforced mortars and ternary concretes after exposed to a chloride solution for a long period [42-43]. In those studies, the SCBA was only sieved through the $75 \mu \mathrm{m}$ ASTM mesh.

\section{Discussion}

According to the literature, the SCBA can be used as partial cement replacement up to $30 \%$ without negative effects on the compressive strength of cement-based composites [2-3, 39]. However, some research results suggest that the SCBA needs a post-treatment to enhance its pozzolanic properties in cement-based composites [8]. From this, sieving appears to be the lower energy consumption post-treatment. However, only few studies report about the performance of sieved SCBA in cement-based composites. To address this, a comprehensive long-term research project about the use of practically "as received" SCBA (a SCBA sieved by the $75 \mu \mathrm{m}$ ASTM mesh during 4 to 5 minutes) from sugar mills in cement-based composites is ongoing. As an outcome from the project, the rheological [28], microstructural [10, 29] and some durability properties [26, 42-43] of cement-based composites containing that SCBA has been evaluated. The authors conclude that a sieving process for the SCBA is enough to enhance the mentioned properties of the composites. As a follow up the longterm project, further evaluations about the effect of sieved SCBA on the corrosion of reinforced composites are needed. 


\section{Conclusions}

The use of SCBA as partial cement replacement in cement-based composites can provide a break-through for a more environmentally-friendly and sustainable construction industry in addition of the benefits against environmental pollution by the use of a waste material

The SCBA can be used as partial Portland cement replacement in order to enhance the microstructural and mechanical properties of cement-based composites. All in all, an extensive research about durability of those composites added with SCBA is needed.

Further research projects about the use of SCBA subjected to a low-energy demand post-treatment in cement-based composites is suggested for sustainable efforts. Durability of those composites must extensively be evaluated.

\section{Acknowledgements}

The authors are grateful to the Instituto Politécnico Nacional (IPN) of México, the CIIDIR-IPN and the SIP-IPN for the facilities and financial support providing during the development of this review paper. The authors are also grateful to the Consejo Nacional de Ciencia y Tecnología (CONACyT) for the doctoral scholarship granted to Marco Antonio Maldonado-García.

\section{References}

[1] M. Frías, E. Villar and H. Savastano, "Brazilian sugar cane bagasse ashes from the cogeneration industry as active pozzolans for cement manufacture," Cement Concrete Comp., vol. 33, pp. 490-406, 2011.

[2] S. Dhengare, S. Amrodiya, M. Shelote, A. Asati, N. Bandwaf, K. Anand and R. Jichkar, "Utilization of sugarcane bagasse ash as a supplementary cementitious material in concrete and mortar - A review," International Journal of Civil Engineering and Technology, vol. 6, no. 4, pp. 94-106, 2015.

[3] V. D. Katare and M. V. Madurwar, "Experimental characterization of sugarcane biomass ash - A review", Constr. Build. Mater., vol. 152, pp. 1-15, 2017.

[4] M. M. N. S. Soares, F. S. J. Poggiali, A. C. S. Bezerra, R. B. Figueiredo, M. T. P. Aguilar and P. R. Cetlin, "The effect of the calcination conditions on the physical and chemical characteristics of sugar cane bagasse ash," R. Esc. Minas., vol. 67, pp. 33-39, 2014.

[5] K. Ganesan, K. Rajagopal, K. Thangavel, "Evaluation of bagasse ash as supplementary cementitious material," Cement. Concrete Comp., vol. 29, pp. 515-524, 2007.

[6] N. Chusilp, C. Jaturapitakkul, K. Kiattikomol, "Utilization of bagasse ash as a pozzolanic material in concrete," Construct. Build. Mater., vol. 23, no. 11, pp. 3352-3358, 2009.

[7] E. V. Morales, E. Villar-Cociña, M. Frías, S. F. Santos and J. R. H. Savastano, "Effects of calcining conditions on the microstructure of sugar cane waste ashes (SCWA): Influence in the pozzolanic activation," Cement Concrete Comp., vol. 31, no. 1, pp. 22-28, 2009.

[8] A. Bahurudeen and M. Santhanam, "Influence of different processing methods on the pozzolanic performance of sugarcane bagasse ash," Cement Concrete Comp., vol. 56, pp. 32-45, 2015.

[9] G. C. Cordeiro, O- A- Paiva, R. D. Toledo-Fhilo, E. M. R. Fairbairn and L. M. Tavares, "Long term compressive behavior of concretes with sugarcane bagasse ash as a supplementary cementitious material," J. Test. Eval., vol. 46, no. 2, pp. 564-573, 2018.

[10] M. A. Maldonado-García, U. I. Hernández-Toledo, P. Montes-García, P. L. Valdez-Tamez, "The influence of untreated sugarcane bagasse ash on the microstructural and mechanical properties of mortars", Mater. Construcc., vol. 68, no. 329, e148, 2018.

[11] A. Rajasekar, K. Arinachalam, M. Kottaisamy and V. Sraswathy, "Durability characteristics of ultra high strength concrete with treated sugarcane bagasse ash," Construct. Build. Mater., vol. 171, pp. 350-356, 2018.

[12] S. A. Zareei, F. Ameri and N. Bahrami, "Microstructure, strength and durability of eco-friendly concretes containing sugarcane bagasse ash, Construct. Build Mater., vol. 184, pp. 258-268, 2018. 
[13] V. S. Batra, S. Urbonaite, G. Svenson, "Characterization of unburned carbon in bagasse fly ash," Fuel, vol. 87, pp. 2972-2976, 2008.

[14] O. I. Chiparus, "Bagase fiber for production of nonwoven materials," Ph.D. dissertation, Louisiana State University and Agricultural ad Mechanical College, USA, 2004.

[15] D. Verma, P. C. Gope, M. K. Maheshwari and R. K. Sharma, "Bagasse fiber composites - A review," Journal of Materials and Environmental Science, vol. 3, no. 6, pp. 1079-1092, 2012.

[16] A. K. Varma and P. Mondal, "Pyrolysis of sugarcane bagasse in semi bach reactor: Effects of process parameters on product yields and characterization of products," Ind. Crops Prod., vol. 96, pp. 704-717, 2017.

[17] G. C. Cordeiro, R. D. Toledo-Filho and E. M. R. Fairbairn, "Effect of calcination temperature on the pozzolanic activity of sugar cane bagasse ash," Construct. Build. Mater., vol. 23, pp. 3301-3303, 2009.

[18] M. A. Maldonado-García, P. Montes-García, P. L. Valdez-Tamez, "A review of the use of sugarcane bagasse ash with a high LOI content to produce sustainable cement composites," in Proceedings of the 2nd International Conference on Bio-based Building Materials, Clermont-Ferrand, France.

[19] E. Arif, M. Clark and N. Lake, "Sugar cane bagasse ash from a high efficient co-generation boiler: Applications in cement and mortar production," Construct. Build. Mater., vol. 128, pp. 287-297, 2016.

[20] R. V. Ribeiro and M. R. Morelli, "Effect of calcination temperature on the pozzolanic activity of Brazilian sugar cane bagasse ash (SCBA)," Materials Research, vol. 17, pp. 974-981, 2014.

[21] G. C. Cordeiro, R. D. Toledo-Fhilo, L. M. Tavares and E. M. R. Fairbairn, "Ultrafine grinding of sugar cane bagasse ash for application as pozzolanic admixture in concrete," Cement Concrete Res., vol. 39, pp. 110-115, 2009.

[22] N. Chusilp, C. Jaturapitakkul, K. Kiattikomol, "Effects of LOI of ground bagasse ash on the compressive strength and sulfate resistance of mortars," Construct. Build. Mater., vol. 23, pp. 3523-3531, 2009.

[23] R. Somna, C. Jaturapitakkul, P. Rattanachu and W. Chalee, "Effect of ground bagasse ash on mechanical and durability properties of recycled aggregate concrete," Materials and Desing, vol. 36, pp. 597-603, 2012.

[24] G. C. Cordeiro, L. M. Tavares and R. D. Toledo-Fhilo, "Improved pozzolanic activity of sugar cane bagasse ash by selective grinding and classification," Cement Concrete Res., vol. 89, pp. 269-275, 2016.

[25] J. Torres-Agredo, R. Mejía de Gutiérrez, C. E. Escandon-Giraldo, L. O and González-Salcedo, "Characterization of sugar cane bagasse ash as supplementary materials for Portland cement," Ing. Invest., vol. 34, pp. 5-10. 2014.

[26] J. C. Arenas-Piedrahita, P. Montes-García, J. M. Mendoza-Rangel, H. Z. López-Clavo, P. L. Valdez-Tamez and J. Martínez-Reyes, "Mechanical and durability properties of mortars prepared with untreated sugarcane bagasse ash and untreated fly ash," Construct. Build. Mater., vol. 105, pp. 69-81, 2016.

[27] A. Bahurudeen, A. V. Marckson, A Kishore and M Santhebam, "Development of sugarcane bagasse ash based Portland pozzolana cement and evaluation of compativility with superplasticizers," Construct.Build. Mater., vol. 68, pp. 465$475,2014$.

[28] V. G. Jiménez-Quero, F. M. León-Matínez, P. Montes-García, C. Gaona-Tiburcio and J. G. Chacón-Nava, "Influence of sugarcane bagasse ash asd fly ash on the rheological behavior of cement pastes and mortars," Construct. Build. Mater., vol. 40, pp. 691-701, 2013.

[29] V. Ríos-Parada, V. G. Jiménez-Quero, P. L. Valdez-Tamez and P. Montes-García, "Characterization and use of an untreated Mexican sugarcane bagasse ash as supplementary material for the preparation of ternary concretes," Construct. Build. Mater., vol. 157, pp. 83-95, 2017.

[30] E. Câmara, R. C. A. Pinto and J. C. Rocha, "Setting process on mortars containing sugarcane bagasse ash," IBRACON Structures and Materials Journal, vol. 9, no. 4, pp. 617-642.

[31] S. Rukzon and P. Chindaprasirt, "Utilization of bagasse in high-strength concrete," Materials and Desing, vol. 34, pp. 45-50, 2012

[32] G. C. Cordeiro, R. D. Toledo-Fhilo, L. M. Tavares and E. M. R. Fairbairn, "Experimental characterization of binary and ternary blended-cement concretes," Construct. Build. Mater., vol. 29, pp. 641-646, 2012.

[33] G. C. Cordeiro, R. D. Toledo-Fhilo, L. M. Tavares and E. M. R. Fairbairn, "Pozzolanic activity and filler effect of sugar cane bagasse ash," Cement Concrete Comp., vol. 30, no. 5, pp. 410-418, 2008. 
[34] G. C. Cordeiro and K. E. Kurtis, "Effect of mechanical processing on sugar cane bagasse ash pozzolanicity," Cement Concrete Res., vol. 97, pp. 41-49, 2017.

[35] F. Martirena, B. Middendorf, R. L. Day, M. Gehrke, P. Roque, L. Martínez and S. Betancourt, "Rudimentary, low tech incinerators as a means to produce reactive pozzolan out of sugar cane straw," Cement Concrete Res., vol. 36, pp. 10561061, 2006.

[36] P. S. Gar, N. Suresh and V. Bindiganavile, "Sugar cane bagasse ash as a pozzolanic admixture in concrete for resistance to sustained elevated temperatures," Construct. Build. Mater., vol. 153, pp. 929-936, 2017.

[37] A. Bahurudeen, D. Kanraj, V. Gokul Dev and M. Santhanam, "Performance evaluation of sugarcane bagasse ash blended cement in concrete," Cement Concrete Comp., vol. 59, pp. 77-88, 2015.

[38] F. Martirena and J Monzó, "Vegetable ashes as supplementary cementitious materials," Cement Concrete Res., vol. 114, pp. 57-64, 2018.

[39] J. M. Paris, J. G. Roessler, C. C. Ferraro, H. D. DeFord and T. G. Townsend, “A review of waste products utilized as supplements to Portland cement in concrete," Journal of Cleaner Production., vol. 121, pp. 1-18. 2016.

[40] R. E. Nuñez-Jaquez, J. E. Buelna-Rodríguez, C. P. Barrlos-Durstewitz, C. Gaona-Tiburcio and F. Almeraya-Calderón, "Corrosion of modified concrete with sugar cane bagsse ash," International Journal of corrosion., pp. 1-5, 2012.

[41] V. G. Valencia, R. Mejía de Gutierrez, J. Barrera and S. Delvasto, "Durability and corrosion study of reinforced blended mortars with tuff and sugar cane bagasse ash," Revista de la Construcción, vol. 12, pp. 112-122. 2012.

[42] M. A. Maldonado-García, U. I. Hernández-Toledo, P. Montes-García and P. L. Valdez-Tamez, "Long-term corrosion risk of thin cement composites containing untreated sugarcane bagasse ash," J. Mater. Civ. Eng., vol. 31, no. 4, pp. 1$13,2019$.

[43] V. A. Franco-Luján, M. A. Maldonado-García, J. M. Mendoza-Rangel and P. Montes-García, "Chloride-induced reinforcing steel corrosion in ternary concretes containing fly ash and untreated sugarcane bagasse ash," Construct. Build. Mater., vol. 198, pp. 608-618, 2019. 